(c) American Dairy Science Association, 2005.

\title{
Influence of Body Condition Score on Relationships Between Metabolic Status and Oxidative Stress in Periparturient Dairy Cows*
}

\author{
U. Bernabucci, B. Ronchi, N. Lacetera, and A. Nardone \\ Dipartimento di Produzioni Animali, Università della Tuscia, via C. De Lellis, 01100 Viterbo, Italy
}

\begin{abstract}
Twenty-four dairy cows were monitored during the transition period. We observed changes of oxidative status and relationships between oxidative and metabolic status. Body condition score (BCS) of the 24 animals at the beginning of the trial (30.4 $\pm 2 \mathrm{~d}$ before expected calving) was between 2.0 and 3.6. The BCS was recorded and blood samples were collected weekly during the last $30 \mathrm{~d}$ of pregnancy and the first 30 DIM. Plasma samples were analyzed to determine indices of oxidative status: reactive oxygen metabolites (ROM); thiobarbituric acid-reactive substances (TBARS); thiol groups (SH); glutathione peroxidase (GSH-Px), and indices of energy metabolism: glucose, $\beta$-hydroxybutyrate, and nonesterified fatty acids. In erythrocytes we determined indices of oxidative status: GSH-Px, superoxide dismutase (SOD), and intracellular SH. Before calving, cows showed an increase of plasma SH, SOD, and GSH$\mathrm{Px}$, a decrease of erythrocyte GSH-Px and plasma ROM, and no changes in erythrocyte SH. After calving, cows showed a decrease of plasma and erythrocyte $\mathrm{SH}$ and SOD, and an increase of ROM, TBARS, and plasma GSH-Px. Cows with higher BCS at the beginning of the trial and greater loss of BCS after calving, had higher plasma ROM, TBARS, and SH, and lower SOD and erythrocyte $\mathrm{SH}$ in the postpartum period. Oxidative status of dairy cows was related to energy status. Cows with higher BHBA and NEFA showed higher ROM and TBARS and lower levels of antioxidants. Results of the present study demonstrated that cows can experience oxidative stress during the peripartum period, and cows with higher BCS and greater BCS losses are more sensitive to oxidative stress.
\end{abstract}

(Key words: dairy cow, transition period, oxidative status, metabolic status)

Abbreviation key: GSH-Px = Se-glutathione peroxidase, HBCS = high BCS, LBCS = low BCS, MBCS =

Received September 23, 2004.

Accepted February 16, 2005.

Corresponding author: U. Bernabucci; e-mail: bernab@unitus.it.

*The research was financially supported by MIUR (Special Project FIRB) and RSA 2004. medium BCS, $\mathbf{P C V}$ = packed cell volume, $\mathbf{R O M}=$ reactive oxygen metabolites, $\mathbf{S H}=$ thiol groups, $\mathbf{S O D}=$ CuZn-superoxide dismutase, TBARS = thiobarbituric acid-reactive substances.

\section{INTRODUCTION}

Oxidative stress in a living organism is a result of an imbalance between reactive oxygen metabolites (ROM) production and neutralizing capacity of antioxidant mechanisms (Sies, 1991). Oxidative stress leads to peroxidative damage of lipids and other macromolecules, with consequent alteration of cell membranes and other cellular components (Toyokuni, 1999). Oxidative stress can lead to the modification of important physiological and metabolic functions. Some researchers (Miller et al., 1993; 1994) reported that oxidative stress could alter the physiology and could cause pathologies.

The transition period is particularly important for health and subsequent performance of dairy cows, which are exposed to drastic physiological changes and metabolic stress (Grummer, 1993; Goff and Horst, 1997; Drackley, 1999). Relationships between BCS and incidence of metabolic diseases have been exhaustively reported (Gearhart et al., 1990; Studer, 1998). It has been hypothesized that an involvement of oxidative stress during transition period is the etiology of some diseases and disorders in dairy cows (Harrison et al., 1984; Smith et al., 1984; Gröhn et al., 1989; Lomba, 1996).

In humans, recent studies showed a close relationship between high body mass index, body weight loss, and oxidative stress (Ozata et al., 2002; Higdon and Frei, 2003; Keaney et al., 2003), and researchers hypothesized a possible relationship between oxidative stress and incidence of some metabolic diseases (Higdon and Frei, 2003; Morrow, 2003).

Our hypothesis is that oxidative status might also be related to metabolic disorders in dairy cows. To date, there is no information available concerning the relationship between changes in oxidative status indices and metabolic status in periparturient dairy cows. In the present study, we evaluated oxidative status and assessed the possible relationships between oxidative and metabolic status in periparturient dairy cows. 
Table 1. Ingredient and nutrient compositions of diets administered during the experimental period.

\begin{tabular}{|c|c|c|c|}
\hline Ingredient (\% of DM) & $\begin{array}{l}\text { Far-off } \\
\text { dry cows }\end{array}$ & $\begin{array}{l}\text { Close-up } \\
\text { dry cows }\end{array}$ & $\begin{array}{l}\text { Lactating } \\
\text { cows }\end{array}$ \\
\hline Corn silage & 11.90 & 18.80 & 26.40 \\
\hline Rye-grass silage & 3.20 & 5.00 & 7.00 \\
\hline Alfalfa hay & 4.30 & 6.80 & 9.60 \\
\hline Rye-grass hay & 58.50 & 34.10 & 7.70 \\
\hline Commercial mixed feed ${ }^{1}$ & 6.10 & 9.60 & 13.50 \\
\hline Corn, ground & 6.20 & 9.80 & 13.70 \\
\hline Oat, ground & 4.00 & 6.20 & 8.70 \\
\hline Wheat middlings flour & 2.10 & 3.30 & 4.70 \\
\hline Cotton seed & 2.90 & 4.70 & 6.60 \\
\hline Mineral premix ${ }^{2}$ & 1.00 & 1.60 & 2.20 \\
\hline \multicolumn{4}{|c|}{ Nutrient composition on DM basis } \\
\hline $\mathrm{NE}_{\mathrm{L}}, \mathrm{Mcal} / \mathrm{kg}$ & 1.30 & 1.40 & 1.55 \\
\hline Crude proteins, $\%$ & 12.30 & 14.20 & 16.60 \\
\hline $\mathrm{NDF}, \%$ & 42.10 & 38.20 & 34.10 \\
\hline
\end{tabular}

${ }^{1}$ Contained $87 \% \mathrm{DM}, 23.7 \% \mathrm{CP}$ and $1.89 \mathrm{Mcal} / \mathrm{kg}$ on DM basis and $100,000 \mathrm{IU}$ of vitamin A, $8000 \mathrm{IU}$ of vitamin $\mathrm{D}, 100 \mathrm{mg}$ of vitamin $\mathrm{E}, 500 \mathrm{mg}$ of niacin, $10.4 \mathrm{mg}$ of vitamin $\mathrm{B}_{1}, 14 \mathrm{mg}$ of vitamin $\mathrm{B}_{2}, 4 \mathrm{mg}$ of vitamin $\mathrm{B}_{6}, 0.1 \mathrm{mg}$ of vitamin $\mathrm{B}_{12}, 200 \mathrm{mg}$ of $\mathrm{Fe}, 30 \mathrm{mg}$ of $\mathrm{Cu}, 160 \mathrm{mg}$ of $\mathrm{Mg}, 4.4 \mathrm{mg}$ of $\mathrm{Co}, 10.8 \mathrm{mg}$ of $\mathrm{I}$, $360 \mathrm{mg}$ of $\mathrm{Zn}$, and $0.6 \mathrm{mg}$ of Se per kilogram.

${ }^{2} \mathrm{~A}$ mixture of $33.3 \% \mathrm{CaCO}_{3}, 31.7 \mathrm{Ca}_{3}\left(\mathrm{PO}_{4}\right)_{2}, 16.7 \% \mathrm{MgO}, 16.6 \% \mathrm{NaHCO}_{3}$, and $1.7 \% \mathrm{ZnSO}_{4}$.

\section{MATERIALS AND METHODS}

\section{Animals, Housing, and Feeding}

The trial was carried out in a commercial dairy herd consisting of 290 lactating cows. The average milk yield per lactation (305-DIM) of the herd was more than 9000 $\mathrm{kg}$. Twenty-four pregnant Holstein cows (10 primiparous, 7 at second calving, and 7 at third calving) were selected based on their BCS, parity, and expected calving date. In particular, cows with BCS $<2.5$, BCS from 2.6 to 3.0 , and BCS $>3.0$ were assigned to low (LBCS), medium (MBCS), and high (HBCS) BCS groups, respectively. Mean values of BCS at $30.4 \pm 2 \mathrm{~d}$ before calving were $2.3 \pm 0.2,2.8 \pm 0.1$, and $3.2 \pm 0.2$ in LBCS, MBCS, and HBCS, respectively. Body condition score was statistically different between the 3 groups $(P<$ 0.01 ). The 3 groups of 8 healthy cows were balanced across expected calving date and parity. The animals were monitored during the last $30 \mathrm{~d}$ of pregnancy and the first 30 DIM. The average ( \pm SD) parity was: 1.9 $\pm 0.8,1.9 \pm 0.9$, and $1.9 \pm 0.8$ in LBCS, MBCS, and HBCS, respectively.

The diets administered during the trial consisted of a base ration given ad libitum to achieve 5 to $10 \%$ feed refusals as a daily TMR (at $\sim 0930 \mathrm{~h}$ ). The composition of the diet used during the experiment (far-off dry, closeup, and lactation diet) is reported in Table 1. The closeup diet was offered during the last $10 \mathrm{~d}$ before the expected calving.

\section{Measurements and Sampling}

Dry matter of feedstuffs was determined by forcedair oven drying at $65^{\circ} \mathrm{C}$ to constant weight. Crude pro- tein was determined by macro-Kjeldahl method (AOAC, 1984). Ether extract and ash were determined according to AOAC methods (AOAC, 1984). The NDF was analyzed according to the method described by Goering and Van Soest (1970).

During the trial, BCS was recorded and blood samples were taken weekly from each animal. Body condition was scored by the same person adopting a 5-point scale method (ADAS, 1986). Bleeding was carried out using evacuated tubes containing Li-heparin as anticoagulant. Body condition score was recorded and blood samples were taken from the jugular vein at d $30.4 \pm$ $2.0,24.7 \pm 2.4,17.6 \pm 2.2,10.8 \pm 2.2$, and $3.9 \pm 1.6$ prepartum and at $4,11,18,25$, and $30 \mathrm{~d}$ postpartum. Whole blood was used to determine packed cell volume (PCV) by microhemocytometer. Blood samples were centrifuged at $2700 \times g$ for $10 \mathrm{~min}$ at $4^{\circ} \mathrm{C}$ and plasma was separated. Plasma samples were analyzed to determine glucose (Instrumentation Laboratory, Lexington, MA), BHBA (Barnouin et al., 1986), and NEFA (NEFAC kit, Wako Fine Chemical Industries Inc., Dallas, TX). The following indices of oxidative status were analyzed in plasma samples: Se-glutathione peroxidase (GSH$\mathbf{P x})$ activity, thiol groups (SH) concentration, ROM, and thiobarbituric acid-reactive substances (TBARS) concentration.

Erythrocytes were obtained by centrifuging $0.5 \mathrm{~mL}$ of blood at $2200 \times \mathrm{g}$ for $10 \mathrm{~min}$ at $4^{\circ} \mathrm{C}$. Erythrocytes were then washed 4 times with $3 \mathrm{~mL}$ of $0.9 \% \mathrm{NaCl}$ solution for $10 \mathrm{~min}$ at $2200 \times \mathrm{g}$ at $4^{\circ} \mathrm{C}$. After the final wash, red blood cells were lysed by hypotonic shock using $2.0 \mathrm{~mL}$ of cold ultrapure water. The hemolysate was mixed and left at $4^{\circ} \mathrm{C}$ for $15 \mathrm{~min}$. Erythrocyte lysate was analyzed to determine intracellular SH concentra- 
tion, CuZn-superoxide dismutase (SOD) activity, and GSH-Px activity.

\section{Analysis of Oxidative Status Indices}

SOD assay. CuZn-superoxide dismutase activity in erythrocyte lysate was measured by a kinetic method using a commercial kit (RANSOD, Randox Laboratories, UK). Briefly, erythrocyte lysate was diluted 25fold with $0.01 \mathrm{mmol} / \mathrm{L}$ phosphate buffer, $\mathrm{pH}$ 7.0. This method employs xanthine and xanthine oxidase to generate superoxide radicals that react with 2-(4-iodophenil)-3-(4-nitrophenol)-5-phenitetrazolium chloride. This reaction gives a red formazan dye. The SOD activity is then measured through the degree of inhibition of the reaction. The increase in absorbance is followed at $505 \mathrm{~nm}$ for $3 \mathrm{~min}$. Phosphate buffer or various standard concentrations in place of the sample were used as blank or standard determination. Superoxide dismutase activity was expressed in units per milliliter of PCV.

GSH-Px assay. Activity of GSH-Px in plasma and erythrocyte lysate was determined by a kinetic method using a commercial kit (RANSEL, Randox Laboratories). The method is based on Paglia and Valentine's (1967) work. Glutathione peroxidase catalyzes the oxidation of glutathione by cumene hydroperoxide. In the presence of glutathione reductase and $\mathrm{NADPH}$, the oxidized glutathione is immediately converted to the reduced form with a concomitant oxidation of NADPH to $\mathrm{NADP}^{+}$. The decrease in absorbance was followed at $340 \mathrm{~nm}$ for $3 \mathrm{~min}$. Enzyme activity was reported in units per milliliter of PCV in erythrocytes and in units per milliliter in plasma.

Plasma SH assay. Concentration of $\mathrm{SH}$ groups was measured in plasma by a colorimetric method using a commercial kit (SHp Test; Diacron, Grosseto, Italy). The method is based on the capacity of sulfhydryl groups present in the plasma sample to react with 5,5'dithiobis-(2-nitrobenzoic acid) and form a yellow dye with maximum absorbance at $405 \mathrm{~nm} .5,5^{\prime}$-Dithiobis-(2nitrobenzoic acid) or various standard concentrations in place of sample were used as blank or for standard determination. Plasma SH concentration was expressed in micromoles per liter.

Intracellular SH assay. Cytosolic thiols content was determined using a commercial kit (SHp Test; Diacron) following the method reported by Kusmic et al. (2000a). Briefly, it used $0.5 \mathrm{~mL}$ of erythrocyte lysate. Proteins were precipitated by the addition of $1 \mathrm{~mL}$ of fresh metaphosphoric acid solution (1.67 $\mathrm{g}$ of metaphosphoric acid, $0.2 \mathrm{~g}$ of EDTA-disodium salt, and $30 \mathrm{~g}$ of $\mathrm{NaCl}$ in $100 \mathrm{~mL}$ of $\mathrm{H}_{2} \mathrm{O}$ ). After $5 \mathrm{~min}$, the supernatant was separated from protein precipitate by centrifuga- tion and subsequently filtered on Puradisc 25AS 0.2$\mu \mathrm{m}$ pore size filter (Whatman, Maidstone, UK). Intracellular SH concentration of supernatant was measured as reported for plasma SH. Intracellular SH concentration was expressed in micromoles per milliliter of PCV.

Plasma ROM assay. Reactive oxygen metabolites were measured in plasma using a method patented by Diacron (d-ROM test; Diacron) (Cesarone et al., 1999). The principle of this method is based on the capacity of transition metals, when changed from the chelated state into transport and deposit proteins (as generally found in plasma), to catalyze reactions of formation of ROM (following Fenton's reaction) or on radical propagation during lipid peroxidation. The oxyradical species produced were trapped by an alchylamine, a phenolic compound able to react forming a colored stable radical detectable by photometry at $505 \mathrm{~nm}$ (Kusmic et al., 2000b). The results were expressed in U. Carr. units. The value of $1 \mathrm{U}$. Carr. unit corresponded to a concentration of $0.08 \mathrm{mg} / 100 \mathrm{~mL}$ of $\mathrm{H}_{2} \mathrm{O}_{2}$.

Plasma TBARS assay. Plasma levels of TBARS were determined following the method described by Maseki et al. (1981). After the reaction of thiobarbituric acid with malondialdehyde, the product of reaction is extracted in butanol and is measured spectrofluorometrically $($ excitation $=515 \mathrm{~nm}$, emission $=553 \mathrm{~nm}$ ). 1,1,3,3-Tetraethoxypropane was used as standard, and TBARS levels in plasma were expressed in nanomoles per milliliter.

\section{Statistical Analyses}

Data for all measured variables were analyzed as repeated measures using the MIXED procedure of SAS (SAS Institute, 1999). Three models were used. The first was used to estimate the sampling day effect on indices of oxidative status:

$$
\mathrm{Y}_{\mathrm{ij}}=\mu+\mathrm{D}_{\mathrm{i}}+\mathrm{e}_{\mathrm{ij}}
$$

where $Y_{i j}=$ dependent variable; $\mu=$ overall mean of the population; $D_{i}=$ mean effect of day of sampling ( $\mathrm{i}=1, \ldots 10)$ with day as a repeated factor; and $\mathrm{e}_{\mathrm{ij}}=$ unexplained residual element assumed to be independent and normally distributed. For each analyzed variable, cows were subjected to 3 covariance structures: compound symmetric, autoregressive order one, and unstructured covariance.

The second model was used to estimate sampling day effect, BCS group, and the interaction on BCS, NEFA, and BHBA:

$$
\mathrm{Y}_{\mathrm{ijk}}=\mu+\mathrm{D}_{\mathrm{i}}+\mathrm{BCS}_{\mathrm{j}}+\left(\mathrm{D} \times \mathrm{BCS}_{\mathrm{ij}}+\mathrm{e}_{\mathrm{ijk}}\right.
$$




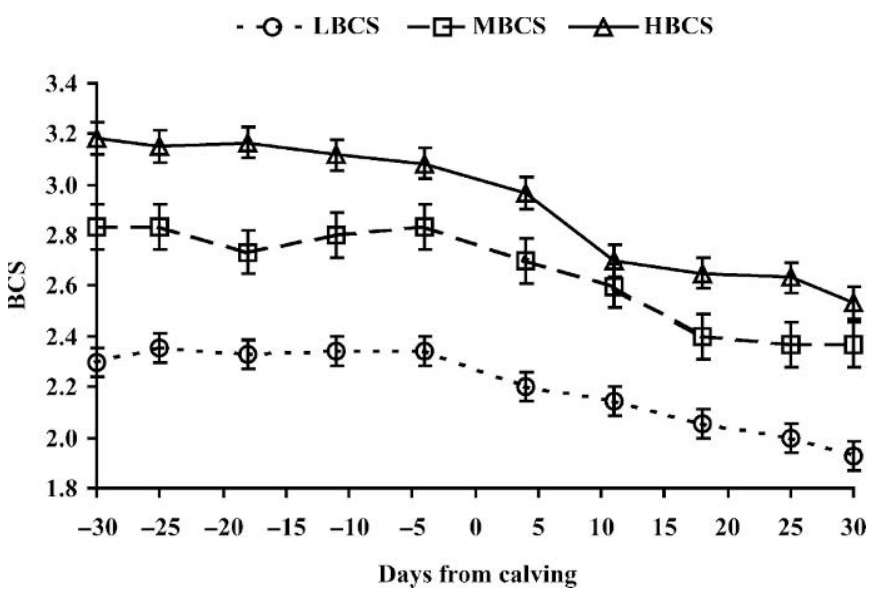

Figure 1. Least square means $\pm \mathrm{SE}$ of BCS in cows with BCS $<$ 2.5 (LBCS), BCS from 2.6 to 3.0 (MBCS), and BCS > 3.0 (HBCS).

where $\mathrm{Y}_{\mathrm{ijk}}=$ dependent variable; $\mu=$ overall mean of the population; $D_{i}=$ mean effect of day of sampling $(i=$ $1, \ldots 10)$ with day as a repeated factor; $\mathrm{BCS}_{\mathrm{j}}=$ mean effect of BCS group $(\mathrm{j}=1, . .3)$; and $\mathrm{e}_{\mathrm{ij}}=$ unexplained residual element assumed to be independent and normally distributed. For each analyzed variable, cows within BCS group were subjected to 3 covariance structures: compound symmetric, autoregressive order one, and unstructured covariance.

The third model was used to estimate the effect of physiological phase, BCS group, and the interaction on indices of oxidative status:

$$
\mathrm{Y}_{\mathrm{ijk}}=\mu+\mathrm{P}_{\mathrm{i}}+\mathrm{BCS}_{\mathrm{j}}+(\mathrm{P} \times \mathrm{BCS})_{\mathrm{ij}}+\mathrm{e}_{\mathrm{ijk}}
$$

where $\mathrm{Y}_{\mathrm{ijk}}=$ dependent variable; $\mu=$ overall mean of the population; $\mathrm{P}_{\mathrm{i}}=$ mean effect of physiological phase (i = prepartum, postpartum) with physiological phase as a repeated factor; $\mathrm{BCS}_{\mathrm{j}}=$ mean effect of BCS group $(j=1, . .3)$; and $e_{i j}=$ unexplained residual element assumed to be independent and normally distributed. For each analyzed variable, cows within BCS group were subjected to 3 covariance structures: compound symmetric, autoregressive order one, and unstructured covariance.

Data were analyzed across sampling days relative to day of calving with $\mathrm{d} 0$ representing the day of calving. Day of calving was considered as a postpartum variable.

The covariance structure that had the largest Akaike's information criterion and Schwarz's Bayesian criterion was considered the most desirable analysis (Littell et al., 1998). Least square means were separated using the PDIFF procedure of SAS (SAS Institute, 1999). For all parameters tested, the best covariance structure was compound symmetric. Correlation coef-
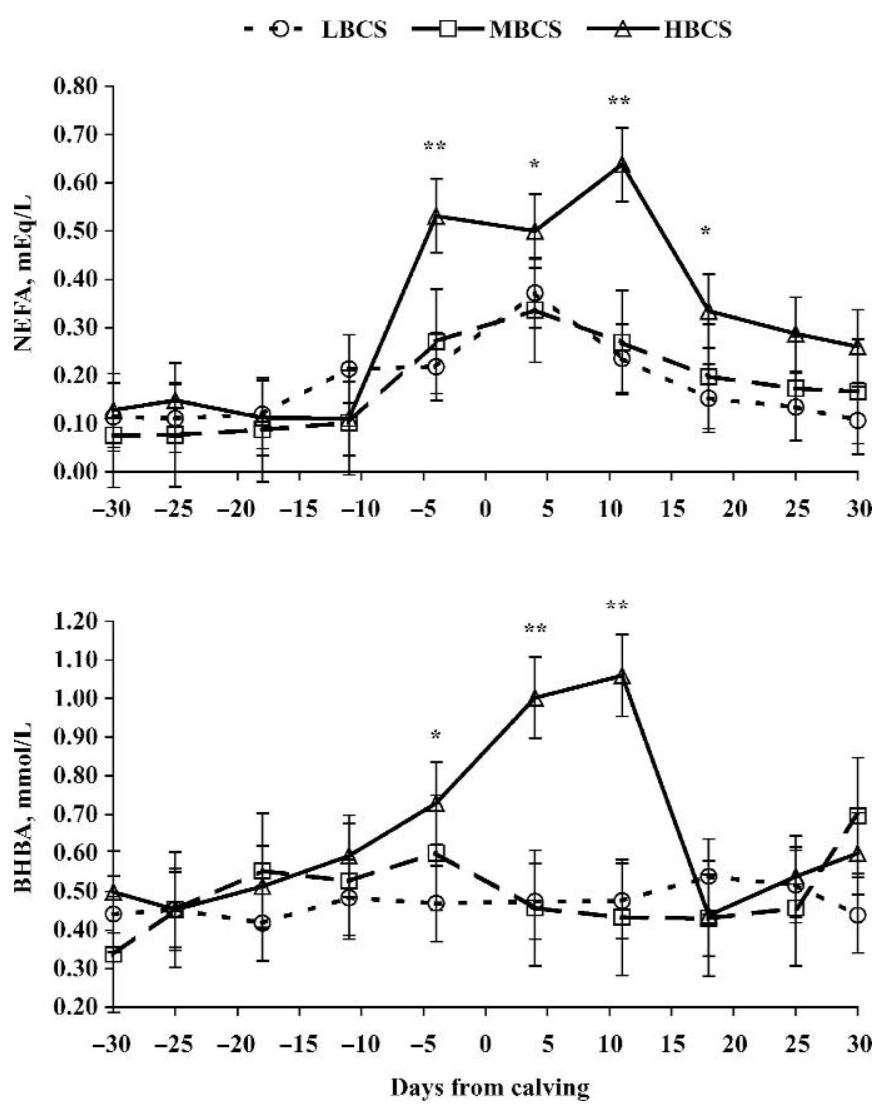

Figure 2. Least square means $\pm \mathrm{SE}$ of plasma NEFA and BHBA in cows with BCS $<2.5$ (LBCS), BCS from 2.6 to 3.0 (MBCS), and BCS $>3.0$ (HBCS). $* P<0.05, * * P<0.01$ between HBCS and MBCS or LBCS groups. No differences were observed between MBCS and LBCS groups.

ficients among different variables were determined using the CORR procedure of SAS (SAS Institute, 1999). Significance was declared at $P<0.05$.

\section{RESULTS}

\section{BCS and Metabolic Parameters}

None of the 24 cows showed cases of clinical diseases or disorders around calving.

Changes of BCS in each of the 3 groups of cows are reported in Figure 1. The HBCS group showed higher $(P<0.05)$ BCS reduction from late pregnancy to 30 DIM than LBCS and MBCS groups (-0.6 in HBCS vs. -0.3 in MBCS and LBCS groups).

Plasma glucose concentration did not differ among the 3 groups (data not shown). The HBCS cows had higher plasma BHBA and NEFA before $(P<0.05)$ and after $(P<0.01)$ calving (Figure 2$)$. After calving, significant positive correlations were found between BCS decline and BHBA $(\mathrm{r}=0.45, P<0.01)$ and NEFA $(\mathrm{r}=$ 


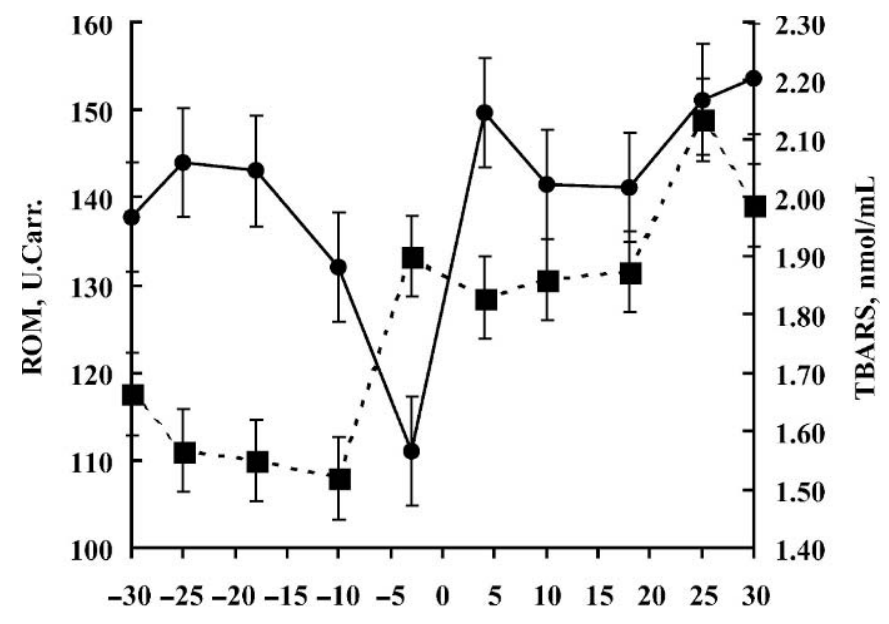

Days from calving

Figure 3. Least square means $\pm \mathrm{SE}$ of plasma reactive oxygen metabolites (ROM, ๑), and thiobarbituric acid-reactive substances (TBARS, - ) in dairy cows during the transition period. U. Carr. is an arbitrary measure unit; $1 \mathrm{U}$. Carr. corresponds to $0.08 \mathrm{mg}$ of $\mathrm{H}_{2} \mathrm{O}_{2} /$ $100 \mathrm{~mL}$.

$0.51, P<0.01)$. Those relationships indicated that cows with higher BCS losses had also higher plasma BHBA and NEFA.

\section{Oxidative Status}

Changes of oxidative status indices during the transition period as mean of the 24 cows are reported in Figures 3, 4, and 5 .

Plasma concentration of ROM is relatively steady with the exception of a dramatic drop $(P<0.05)$ just before calving. Immediately after calving, ROM increased and reached levels slightly higher than those observed in the period from 30 to $20 \mathrm{~d}$ before calving. Plasma concentration of TBARS began to increase during the last week of pregnancy and reached the maximum at 25 DIM. This change resulted in higher values after calving compared with those observed before calving $(1.9$ vs. $1.6 \mathrm{nmol} / \mathrm{mL}, P<0.05$, after and before calving, respectively).

Plasma SH peaked $4 \mathrm{~d}$ before calving $(P<0.05)$, and after 10 DIM, they were back to the levels registered $30 \mathrm{~d}$ before calving. Intracellular SH showed no changes until calving, and then significantly decreased $(P<0.05)$ after calving. Activity of SOD progressively increased $(P<0.05)$ in the last $3 \mathrm{wk}$ of pregnancy, and reached the maximum $4 \mathrm{~d}$ before parturition. After calving, SOD activity rapidly declined to reach the levels registered before calving. Erythrocyte GSH-Px activity had a distinct drop $(P<0.05)$ between -4 and $+11 \mathrm{~d}$ around calving. Glutathione peroxidase activity of plasma in-
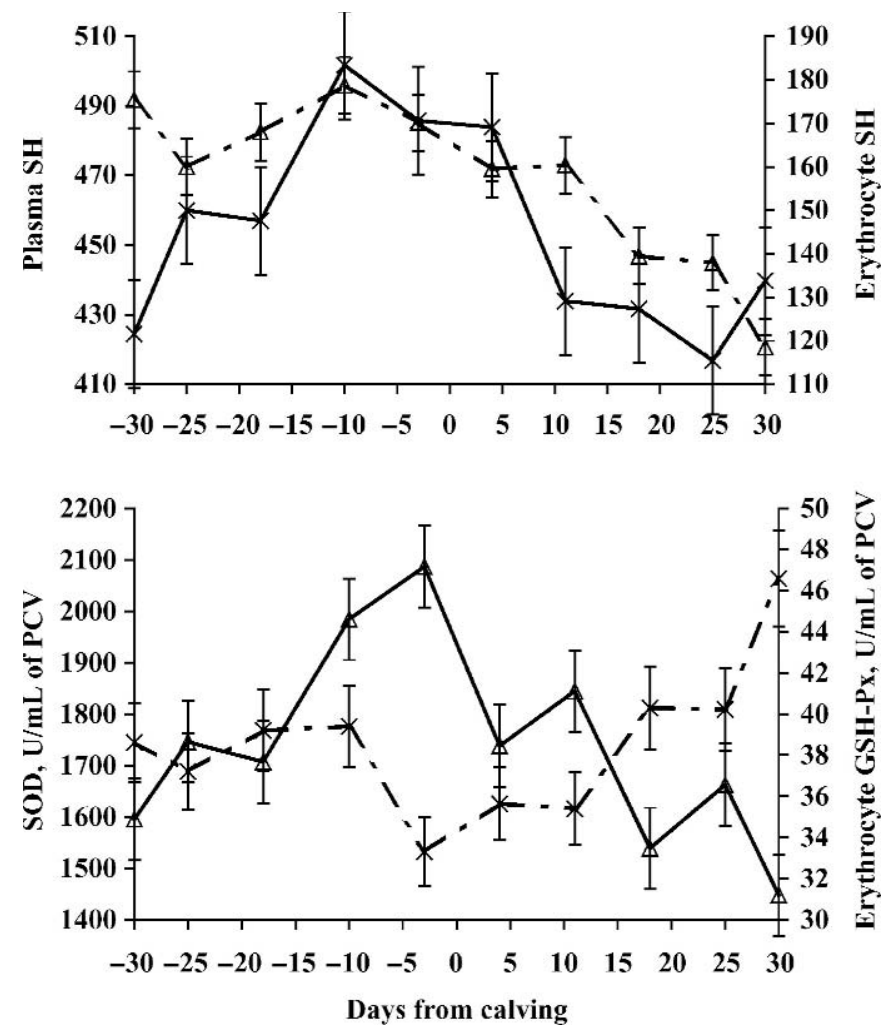

Figure 4. Least square means $\pm \mathrm{SE}$ of plasma thiol groups $(\mathrm{SH}$, $\mu \mathrm{mol} / \mathrm{L})(-)$ and erythrocyte (- - ) $\mathrm{SH}(\mu \mathrm{mol} / \mathrm{mL}$ of PCV) concentrations, erythrocyte glutathione peroxidase (-- ) activity (GSH$\mathrm{Px}$ ), and erythrocyte superoxide dismutase (- ${ }^{-}$activity (SOD) in dairy cows during the transition period. $\mathrm{PCV}=$ Packed cell volume.

creased $(P<0.01)$ from the week before calving until the end of the trial (Figure 5). Plasma GSH-Px showed higher $(P<0.01)$ values after calving compared with data registered before calving (1.60 vs. $0.84 \mathrm{U} / \mathrm{mL}$ after and before calving, respectively).

Cows with higher BCS before calving and with more pronounced BCS losses during the transition period (HBCS group) showed higher plasma ROM $(P<0.01)$

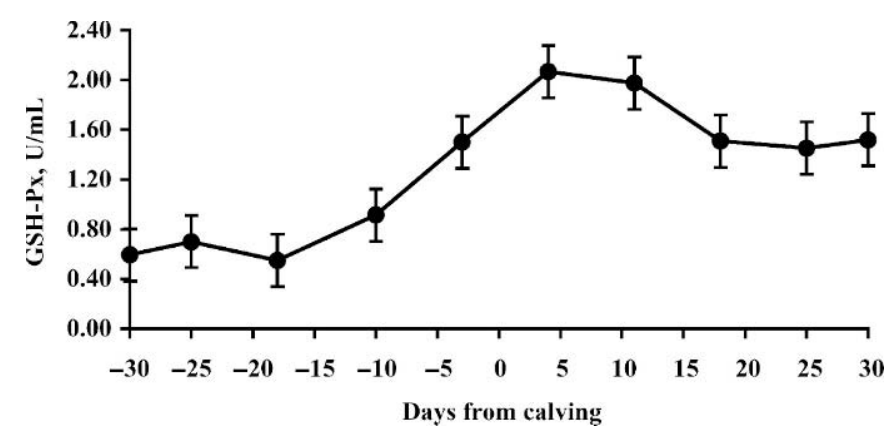

Figure 5. Least square means $\pm \mathrm{SE}$ of plasma glutathione peroxidase activity (GSH-Px) in dairy cows during the transition period. 
Table 2. Plasma reactive oxygen metabolites (ROM) and thiobarbituric acid-reactive substances (TBARS) pre- and postcalving. ${ }^{1}$

\begin{tabular}{lccc}
\hline & \multicolumn{3}{c}{ Treatment group $^{2}$} \\
\cline { 2 - 4 } & LBCS & MBCS & HBCS \\
\hline ROM, U. Carr. & & & \\
$\quad$ Precalving & $137.4 \pm 5.3$ & $128.9 \pm 8.9$ & $142.2 \pm 5.6^{* *}$ \\
Postcalving & $142.2 \pm 3.8^{\mathrm{b}}$ & $129.3 \pm 5.6^{\mathrm{a}}$ & $155.4 \pm 3.7^{\mathrm{c}}$ \\
TBARS, nmol/mL & & & \\
Precalving & $1.57 \pm 0.03$ & $1.55 \pm 0.04$ & $1.50 \pm 0.05^{*}$ \\
Postcalving & $1.77 \pm 0.03^{\mathrm{a}}$ & $1.69 \pm 0.04^{\mathrm{a}}$ & $2.10 \pm 0.06^{\mathrm{b}}$ \\
\hline
\end{tabular}

a,b,c Means between groups within physiological phase differ $(P<$ 0.05).

${ }^{1}$ Least square means $\pm \mathrm{SE}$.

${ }^{2} \mathrm{LBCS}=\mathrm{BCS}<2.5, \mathrm{MBCS}=\mathrm{BCS}$ from 2.6 to 3.0, and HBCS $=$ BCS $>3.0$.

${ }^{3} \mathrm{U}$. Carr. is an arbitrary unit; $1 \mathrm{U}$. Carr. is equivalent to $0.08 \mathrm{mg}$ of $\mathrm{H}_{2} \mathrm{O}_{2} / 100 \mathrm{~mL}$.

${ }^{*} P<0.05$ within group between physiological phases differ.

$* * P<0.01$ within group between physiological phases differ.

and TBARS $(P<0.05)$, lower erythrocyte SH $(P<0.01)$ and SOD $(P<0.01)$, and higher $(P<0.05)$ plasma SH (Tables 2 and 3 ) compared with their counterparts. Furthermore, ROM were positively related to BHBA ( $\mathrm{r}=$ $0.40, P<0.05)$ and NEFA $(\mathrm{r}=0.32 ; P<0.05)$, and NEFA were negatively related with erythrocyte $\mathrm{SH}(\mathrm{r}=-0.32$, $P<0.05)$ and SOD $(\mathrm{r}=-0.29 ; P<0.05)$. No differences were observed in plasma and erythrocyte GSH-Px activity between the 3 groups (Table 3 ). No significant difference was observed in the oxidative status between LBCS and MBCS groups (Tables 2 and 3).

\section{DISCUSSION}

It was previously reported that transition cows with high BCS lose more body weight and body condition than thinner cows (Treacher et al., 1986). Furthermore, it has been reported that high BCS and greater decline of BCS are related to plasma NEFA concentration (Rukkwamsuk et al., 1998) and, possibly, to incidence of metabolic disorders (Cameron et al., 1998; Studer, 1998; Buckley et al., 2003). From the concentration of plasma BHBA observed during the peripartum period in the 3 groups, only the cows of the HBCS group showed a transient, mild ketonemia (Al-Rawashdeh, 1999). Studer (1998) reported that cows with BCS $<2.5$ before calving usually experience postpartum metabolic disorders such as ketosis. On the contrary, LBCS cows that had low plasma NEFA and BHBA levels did not show any sign of metabolic disorders.

The markers of oxidative status were chosen because they have all been implicated in the pathways that link oxidation to pathologic processes. In general, the endogenous antioxidants can be divided into 3 major groups. The first group, enzymatic antioxidants including SOD and GSH-Px, represents the main form of intracellular antioxidant defense. In fact, SOD is considered the first defense against pro-oxidants that convert the superoxide $\left({ }^{\circ} \mathrm{O}_{2}^{-}\right)$to hydrogen peroxide $\left(\mathrm{H}_{2} \mathrm{O}_{2}\right)$, whereas erythrocyte GSH-Px converts $\mathrm{H}_{2} \mathrm{O}_{2}$ into less dangerous reduced forms (Halliwell and Chirico, 1993). The role of plasma GSH-Px as a mere antioxidant device

Table 3. Antioxidants [plasma and erythrocyte thiol groups (SH), erythrocyte glutathione peroxidase (GSHPx) activity, plasma GSH-Px activity and superoxide dismutase (SOD) activity] pre- and postcalving calving. ${ }^{1}$

\begin{tabular}{|c|c|c|c|}
\hline \multirow[b]{2}{*}{ Item } & \multicolumn{3}{|c|}{ Treatment group ${ }^{2}$} \\
\hline & LBCS & MBCS & HBCS \\
\hline \multicolumn{4}{|c|}{ Plasma SH, $\mu \mathrm{mol} / \mathrm{L}$} \\
\hline Precalving & $421.5 \pm 10.9^{\mathrm{A}}$ & $493.6 \pm 13.8^{\mathrm{B}}$ & $507.0 \pm 8.8^{\mathrm{B} *}$ \\
\hline Postcalving & $419.1 \pm 11.3^{\mathrm{A}}$ & $460.8 \pm 12.4^{\mathrm{B}}$ & $468.3 \pm 11.3^{\mathrm{B}}$ \\
\hline \multicolumn{4}{|c|}{ Erythrocyte $\mathrm{SH}, \mu \mathrm{mol} / \mathrm{mL}$ of PCV } \\
\hline Precalving & $169.9 \pm 3.0$ & $151.4 \pm 7.0$ & $164.3 \pm 4.6^{* *}$ \\
\hline Postcalving & $154.9 \pm 4.7^{\mathrm{b}}$ & $159.1 \pm 5.7^{\mathrm{b}}$ & $138.9 \pm 4.0^{\mathrm{a}}$ \\
\hline \multicolumn{4}{|c|}{ Erythrocyte GSH-Px, U/mL of PCV } \\
\hline Precalving & $36.3 \pm 1.0$ & $44.2 \pm 1.6$ & $39.4 \pm 1.7$ \\
\hline Postcalving & $37.0 \pm 1.8$ & $42.7 \pm 2.4$ & $44.8 \pm 1.2$ \\
\hline \multicolumn{4}{|c|}{ Plasma GSH-Px, U/mL } \\
\hline Precalving & $0.97 \pm 0.17 * *$ & $0.65 \pm 0.31^{* *}$ & $0.88 \pm 0.15^{* *}$ \\
\hline Postcalving & $1.55 \pm 0.14$ & $1.61 \pm 0.28$ & $1.59 \pm 0.22$ \\
\hline \multicolumn{4}{|c|}{$\mathrm{SOD}, \mathrm{U} / \mathrm{mL}$ of $\mathrm{PCV}$} \\
\hline Precalving & $1830 \pm 39^{\mathrm{b}}$ & $1560 \pm 112^{\mathrm{a}}$ & $1737 \pm 69^{\mathrm{b} *}$ \\
\hline Postcalving & $1828 \pm 54^{\mathrm{B}}$ & $1587 \pm 78^{\mathrm{A}}$ & $1528 \pm 59^{\mathrm{A}}$ \\
\hline
\end{tabular}

${ }^{\mathrm{a}, \mathrm{b}}$ Means between groups within physiological phase differ $(P<0.05)$.

${ }^{\mathrm{A}, \mathrm{B}}$ Means between groups within physiological phase differ $(P<0.01)$.

${ }^{1}$ Least square means $\pm \mathrm{SE}$.

${ }^{2} \mathrm{LBCS}=\mathrm{BCS}<2.5, \mathrm{MBCS}=\mathrm{BCS}$ from 2.6 to 3.0 , and $\mathrm{HBCS}=\mathrm{BCS}>3.0$.

$* P<0.05$ within group between physiological phases differ.

$* * P<0.01$ within group between physiological phases differ. 
is unclear (Brigelius-Flohé, 1999). However, it was demonstrated that plasma GSH-Px was able to use thioredoxin and glutaredoxin instead of glutathione as a reducing thiol substrate (Björnstedt et al., 1994). Halliwell and Chirico (1993) reported that plasma GSH-Px activity can be related to plasma lipid peroxides content, and Tüzün et al., (2002) considered plasma GSH$\mathrm{Px}$ an indicator of oxidative stress.

The second group, nonenzymatic protein antioxidants, is primarily found in plasma. Total thiol groups of plasma represent the sulfhydryl groups of albumin, L-cysteine, and homocysteine. Protein sulfhydryl groups are considered a significant element of the extracellular antioxidant defense system against oxidative stress (Frei et al., 1988; Uleand et al., 1996).

The third group, the nonenzymatic low-molecularweight antioxidants, is found in plasma and in other extracellular fluids, intracellular fluids, lipoproteins, and membranes. The nonenzymatic low-molecularweight antioxidants can be further subdivided into water-soluble and lipid-soluble antioxidants. Examples of water-soluble antioxidants are ascorbic acid, glutathione, and uric acid. Erythrocyte SH was chosen because its measure provides a good estimation of total intracellular glutathione; it represents about $95 \%$ of the intracellular thiols of red blood cells (van den Berg et al., 1992). We know that glutathione is extremely important because of its numerous functions (Briviba and Sies, 1994): it acts as substrate or cosubstrate in enzymatic reactions (e.g., the glutathione-S-transferase or glutathione-shuttle enzymes); it reacts directly with free radicals and lipid peroxides; and it can protect cells. To evaluate the antioxidant capacity of the cell, glutathione is considered an indicator more useful than intracellular GSH-Px. Moreover, erythrocyte glutathione can reflect the glutathione activity in other tissues.

Other than antioxidants, we also measured ROM and TBARS. Plasma level of ROM is considered an indicator of free radical production (Miller et al., 1993). It is well established that free radicals, especially ${ }^{\circ} \mathrm{O}_{2}^{-}$and other reactive oxygen species like $\mathrm{H}_{2} \mathrm{O}_{2}$ are continuously produced in vivo. The term ROM is a collective one that includes not only oxygen-centered free radicals such as ${ }^{\circ} \mathrm{O}_{2}^{-}$and hydroxyl $\left(\mathrm{OH}^{\cdot}\right)$, but also some nonradical derivatives of oxygen, such as $\mathrm{H}_{2} \mathrm{O}_{2}$, singlet oxygen, and hypochlorous acid (Halliwell and Chirico, 1993). Plasma TBARS were chosen because they have been hypothesized to represent a composite number of lipid oxidative end products, including malondialdehyde. Therefore, TBARS measure is indicative of lipid peroxidation. However, when TBARS are measured in plasma the test is considered a good general indicator of oxidative stress rather than a specific marker of lipid peroxidation (Armstrong and Browne, 1994).
The condition of oxidative stress is the result of an excessive exposure to oxidants and an inadequate availability of antioxidants, or a combination of both (Sies, 1991). In our study, we found that the peripartum period (particularly postpartum) is characterized by a depleted antioxidant status. This physiological phase can impose oxidative stress as indicated by the increase of TBARS and plasma GSH-Px. Our hypothesis is that metabolic and endocrine adjustments, related to metabolism of fetus and mammary gland might be responsible for some variations of the oxidative status in transition cows.

As reported by Miller et al. (1993), the decrease of ROM before parturition might be ascribed to the increase of antioxidant protection that takes place in that particular physiological phase. It is known that the metal-binding macromolecules and protein sulfhydryl groups in extracellular fluid, and SOD and GSH-Px within cells, are the main systems to prevent ROM (Frei et al., 1988). Hermes-Lima et al. (1998) proposed that the activation of antioxidant defenses, in which the actual production of oxyradicals should decrease, is a preparative mechanism against oxidative stress caused by physiological stress situations. Other researchers (Barja de Quiroga et al., 1992) suggested that the entire antioxidant system seems to be under homeostatic control. This means that when the risk of oxidative damage increases, endogenous antioxidant protection increases too. Our previous research (Bernabucci et al., 2002) reported the synchronized increase of SOD, erythrocyte GSH-Px, and intracellular SH in heat-stressed cows. We speculated that those changes were an indirect compensatory response of cells to increased oxidant challenge during heat stress.

The increase of SOD, plasma GSH-Px, and plasma $\mathrm{SH}$ around calving might be the result of a possible homeostatic control. The reduction of erythrocyte GSHPx is not easy to explain; nevertheless, it is possible to suppose that erythrocyte GSH-Px is not involved in the homeostatic response.

To our knowledge, no information is available on the changes in plasma GSH-Px activity around parturition in dairy cows or in other species. The antioxidant role of plasma GSH-Px is not clear (Sies, 1991; BrigeliusFlohé, 1999), and even though plasma GSH-Px appears to be sensitive to body selenium store (Cohen et al., 1985), it does not seem closely related to selenium status (Kirchgessner et al., 1997). However, in a recent study, Tüzün et al. (2002) considered the increase of plasma GSH-Px activity as an indirect indicator of oxidative stress. Taking into account the findings of Tüzün et al. (2002), we speculate that an increase of plasma GSH-Px activity might reflect an altered oxidative status in pre- and postcalving periods. 
Immediately after calving, ROM, TBARS, and plasma GSH-Px increased, and SOD, plasma SH, and erythrocyte $\mathrm{SH}$ began to decrease. These variations might have induced an imbalance between production of ROM and their safe disposal (reduction of antioxidants), and initiated chain reactions and lipid peroxidation. This condition might indicate a loss of homeostatic control in the postpartum period.

Miller et al. (1994) hypothesized that the increase of metabolic rate after calving might be responsible for the elevation of respiratory electron transfer and ROM production. The reduction of erythrocyte antioxidant enzymes in the postpartum period was previously reported (Kankofer et al., 1996; Bernabucci et al., 2002). As is well known, SOD is a $\mathrm{Cu} / \mathrm{Zn}$-dependent enzyme and erythrocyte GSH-Px is a Se-dependent enzyme (Sies, 1991). Reduction in zinc and copper availability in the early postpartum period (Muehlenbein et al., 2001) of dairy cows might explain the reduction of SOD activity (Michiels et al., 1994). Another explanation for the reduction of erythrocyte antioxidant enzymes might derive from the susceptibility of SOD and GSH-Px to the oxidative reactive molecules (Pigeolet et al., 1990).

The alteration of oxidative status after calving might be related to the reduction of plasma and erythrocyte $\mathrm{SH}$ concentration. Plasma protein sulfhydryl groups represent an extracellular antioxidant defense, which effectively decrease the rate of lipid peroxidation (Keaney and Frei, 1994). This reaction leads to a decrease of plasma thiol groups, because the major portion of peroxyl radicals is trapped by plasma sulfhydryl groups (Frei et al., 1988).

Erythrocyte glutathione has direct radical-scavenging ability and represents the substrate for glutathione peroxidase (Brigelius-Flohé, 1999; Jefferies et al., 2003). Moreover, when other antioxidants are inadequate, glutathione is also conjugated by glutathione-Stransferase with peroxyl radicals. This might lead to a net consumption of glutathione (Jefferies et al., 2003).

Albumin is exclusively synthesized by the liver, and it is the main source of plasma SH. Glutathione is mainly synthesized de novo within the liver (Jefferies et al., 2003). The reduction of liver function that is usually observed in the early postpartum might explain lower plasma and erythrocyte SH levels. The concomitant increase of TBARS and plasma GSH-Px, particularly after calving, is indicative of the alteration in the balance between oxidants and antioxidants in favor of the former.

Considering additional data from literature (Goff and Stabel, 1990; Goff and Horst, 1997), the reduction of vitamins $\mathrm{E}$ and $\mathrm{A}$ in plasma might help to explain the alteration of the oxidative status after calving. In this regard, some studies have demonstrated that, besides enhancing plasma level of fast-acting antioxidants, the supplementation of vitamin $\mathrm{E}$ can be useful against oxidative stress in periparturient dairy cows (Weiss et al., 1990; Brzezinska-Slebodzinka et al., 1994).

The novel findings of the present study are the association between BCS, lipid mobilization (NEFA), and the imbalance in oxidative status. Our results demonstrated an association between metabolic status and alteration of oxidative status in transition dairy cows. Cows with higher BCS and greater BCS loss (which had increased concentrations of NEFA and BHBA) were particularly sensitive to oxidative stress. This is highlighted by the higher TBARS and ROM values and lower erythrocyte $\mathrm{SH}$ observed in HBCS cows after calving.

Recent studies demonstrated the relationship between obesity and oxidative stress in humans. Obesity, higher body mass index, and high weight losses were associated with increase of systemic oxidative stress, and with elevated systemic inflammation and activation of coagulation cascade (Chan et al., 2002; Ozata et al., 2002; Morrow, 2003). Some researchers (Higdon and Frei, 2003; Keaney et al., 2003) found an increase of oxidants and a decrease of antioxidants in obese men and women. They concluded that obesity and high body mass index were associated with oxidative stress, which might be linked to obesity diseases and insulin resistance.

Dandona et al. (2004) suggested 2 mechanisms that might be involved in linking obesity and oxidative stress. First, the excessive macronutrients intake; and second, the increased secretion of proinflammatory cytokines (interleukin- 6 and tumor necrosis factor- $\alpha$ ) by adipose tissue in obese individuals.

Yang et al. (2000) demonstrated that mitochondria from fatty livers produce more $\cdot \mathrm{O}_{2}^{-}$and $\mathrm{H}_{2} \mathrm{O}_{2}$ suggesting that chronic oxidative stress contributes to increase hepatocyte necrosis. Other researchers reported that the imbalance of oxidative status might impair liver functionality (Vendemiale et al., 2001; Soltys et al., 2001), contributing to increase the risk of diseases and metabolic disorders in the overconditioned cows in the postpartum period (Gröhn et al., 1989; Lomba, 1996).

In our trial, we cannot consider HBCS cows as overconditioned or obese; nevertheless, as reported in humans (Higdon and Frei, 2003; Keaney et al., 2003; Morrow, 2003), oxidative stress generated by high loss of body reserves might cause metabolic disorders, the genesis of tissue injuries, impairment of functions, and increased incidence of pathologies.

\section{CONCLUSIONS}

Dairy cows during the transition period showed some variations of the oxidative status related to metabolic 
status. When ROM are produced faster than they can be neutralized by antioxidant mechanisms, oxidative stress can result. The increase of TBARS immediately before and particularly after calving confirms that cows during the transition period are under oxidative stress conditions. Among oxidative status indices measured in the present study, erythrocyte SH, TBARS, and plasma GSH-Px were the better measures of oxidative status in transition dairy cows. Plasma GSH-Px needs to be studied further to confirm its possible role as an indicator of oxidative stress in transition dairy cows.

After calving, cows that had high BCS at calving and high lipid mobilization have a more pronounced alteration of oxidative status. These conditions can make cows more sensitive to oxidative stress. Our results highlight the need for further investigation of the possible role of oxidative stress in determining disorders related to obesity in transition dairy cows.

\section{ACKNOWLEDGMENTS}

The authors acknowledge C. Bruti and R. Signorelli for their technical help and V. Buzzavo for advice regarding the English language.

\section{REFERENCES}

ADAS (Agricultural Development and Advisory Service). 1986. Condition scoring of dairy cows. Publ. 612, Agric. Dev. Advisory Serv., Min. Agric., Fisheries Food, Lion House, Alnwick, Northumberland, UK.

Al-Rawashdeh, O. F. 1999. Prevalence of ketonemia and associations with herd size, lactation stage, parity and postparturient diseases in Jordanian dairy cattle. Prev. Vet. Med. 40:117-125.

AOAC. 1984. Official Methods of Analysis. 14th ed. Association of Official Analytical Chemists, Washington, DC.

Armstrong, D., and R. Browne. 1994. The analysis of free radicals, lipid peroxides, antioxidant enzymes and compounds related to oxidative stress as applied to the clinical chemistry laboratory. Adv. Exp. Med. Biol. 366:43-58.

Barja de Quiroga, G., M. Lopez-Torres, and R. Perez-Campo. 1992. Relationship between antioxidants, lipid peroxidation and aging. EXS 62:109-123.

Barnouin, J., N. El-Idilbi, Y. Chilliard, J. P. Chacornac, and R. Lefaivre. 1986. Automatic micro-dosage without deproteinization of bovine plasma 3-hydroxybutyrate. Ann. Rech. Vet. 17:129-139.

Bernabucci, U., B. Ronchi, N. Lacetera, and A. Nardone. 2002. Markers of oxidative status in plasma and erythrocytes of transition dairy cows during hot season. J. Dairy Sci. 85:2173-2179.

Björnstedt, M., J. Xue, W. Wang, B. Akesson, and A. Holmgren. 1994. The thioredoxin and glutaredoxin systems are efficient electron donors to human plasma glutathione peroxidase. J. Biol. Chem. 265:454-461.

Brigelius-Flohé, R. 1999. Tissue-specific functions of individual glutathione peroxidase. Free Radic. Biol. Med. 27:951-965.

Briviba, K., and H. Sies. 1994. Nonenzymatic antioxidants defense system. Pages 107-128 in Natural antioxidants in human health and disease. B. Frei, ed. Academic Press Ltd., San Diego, CA.

Brzezinska-Slebodzinka, E., J. K. Miller, J. D. Quigley, III, J. R. Moore, and F. C. Madsen. 1994. Antioxidant status of dairy cows supplemented prepartum with vitamin E and selenium. J. Dairy Sci. 77:3087-3095.

Buckley, F., K. O'Sullivan, J. F. Mee, R. D. Evans, and P. Dillon. 2003. Relationships among milk yield, body condition, cow weight, and reproduction in spring-calved Holstein-Friesians. J. Dairy Sci. 86:2308-2319.

Cameron, R. E. B., P. B. Dyk, T. H. Herdt, J. B. Kaneene, R. Miller, H. F. Bucholtz, J. S. Liesman, M. J. VanDehaar, and R. S. Emery. 1998. Dry cow diet, management, and energy balance as risk factors for displacement abomasums in high producing dairy herds. J. Dairy Sci. 81:132-139.

Cesarone, M. R., G. Belcaro, and M. Caratelli. 1999. A simple test to monitor oxidative stress. Int. Angiol. 18:127-130.

Chan, J. C., J. C. Cheung, C. D. Stchouwer, J. J. Emeis, P. C. Tong, G. T. Ko, and J. S. Yudkin. 2002. The central role of obesityassociated dyslipidaemia, endothelial activation and cytokines in the metabolic syndrome-An analysis by structural equation modeling. Int. J. Obes. Relat. Metab. Disord. 26:994-1008.

Cohen, H. J., M. E. Chovaniec, D. Mistretta, and S. S. Baker. 1985. Selenium repletion and glutathione peroxidase-differential effects on plasma and red blood cell enzyme activity. Am. J. Clin. Nutr. 41:735-747.

Dandona, P., A. Aljada, and A. Bandyopadhyay. 2004. Inflammation: the link between insulin resistance, and obesity and diabetes. Trends Immunol. 25:4-7.

Drackley, J. K. 1999. Biology of dairy cows during the transition period: The final frontier? J. Dairy Sci. 82:2259-2273.

Frei, B., R. Stocker, and B. N. Ames. 1988. Antioxidant defenses and lipid peroxidation in human blood plasma. Proc. Natl. Acad. Sci. USA 85:9748-9752.

Gearhart, M. A., C. R. Curtis, H. N. Erb, R. D. Smith, C. J. Sniffen, L. E. Chase, and M. D. Cooper. 1990. Relationship of changes in condition score to cow health in Holstein. J. Dairy Sci. 73:3132-3140.

Goering, H. K., and P. J. Van Soest. 1970. Forage fiber analyses (Apparatus, Reagents, Procedures, and Some Applications). Agric. Handbook No. 379. ARS-USDA, Washington, DC.

Goff, J. P., and R. L. Horst. 1997. Physiological changes at parturition and their relationship to metabolic disorders. J. Dairy Sci. $80: 1260-1268$.

Goff, J. P., and J. R. Stabel. 1990. Decreased plasma retinol, alphatocopherol, and zinc concentration during the periparturient period: Effect of milk fever. J. Dairy Sci. 73:3195-3199.

Gröhn, Y. T., H. N. Erb, C. E. McCulloch, and H. S. Saloniemi. 1989. Epidemiology of metabolic disorders of dairy cattle: Association among host characteristics, disease, and production. J. Dairy Sci. $72: 1876-1885$.

Grummer, R. R. 1993. Etiology of lipid-related metabolic disorders in periparturient dairy cows. J. Dairy Sci. 76:3882-3896.

Halliwell, B., and S. Chirico. 1993. Lipid peroxidation: Its mechanism, measurement, and significance. Am. J. Clin. Nutr. 57:715S-725S.

Harrison, J. P., D. D. Hancock, and H. R. Conrad. 1984. Vitamin E and selenium for reproduction of the dairy cow. J. Dairy Sci. 67:123-131.

Hermes-Lima, M., J. M. Storey, and K. B. Storey. 1998. Antioxidants defenses and metabolic depression. The hypothesis of preparation for oxidative stress in land snails. Comp. Biochem. Physiol. B, Biochem. Mol. Biol. 120:437-448.

Higdon, J. V., and B. Frei. 2003. Obesity and oxidative stress. A direct link to CVD? Arterioscler. Thromb. Vasc. Biol. 23:365-367.

Jefferies, H., J. Coster, A. Kahlil, J. Bot, R. D. McCauley, and J. C. Hall. 2003. Glutathione. ANZ J. Surg. 73:517-522.

Kankofer, M., M. Podolak, M. Fidecki, and T. Gontek. 1996. Activity of placental glutathione peroxidase and superoxide dismutase in cows with and without retained fetal membranes. Placenta 17:591-594.

Keaney, J. F., and B. Frei. 1994. Antioxidant protection of low-density lipoprotein and its role in the prevention of atherosclerotic vascular disease. Pages 303-351 in Natural antioxidants in human health and disease. B. Frei, ed. Academic Press Ltd., San Diego, CA.

Keaney, J. F., Jr., M. G. Larson, R. S. Vasan, P. W. F. Wilson, I. L. Lipinska, D. Corey, J. M. Massaro, P. Sutherland, J. A. Vita, and E. J. Benjamin. 2003. Obesity and systemic oxidative stress. Clinical correlates of oxidative stress in the Farmingham study. Arterioscler. Thromb. Vasc. Biol. 23:434-439. 
Kirchgessner, M., S. Gabber, and W. Windish. 1997. Homeostatic adjustment of selenium metabolism and tissue selenium to widely varying selenium supply in selenium labeled rats. J. Anim. Physiol. 78:20-30.

Kusmic, C., E. Picano, C. L. Buscetti, C. Petersen, and R. Maraschi. 2000a. The antioxidant drug dipyridamole spares the vitamin $\mathrm{E}$ and thiols in red blood cells after oxidative stress. Cardiovasc. Res. 47:510-514.

Kusmic, C., C. Petersen, E. Picano, C. Buscetti, G. Parenti, F. Laghi Pasini, and R. Baraschi. 2000b. Antioxidant effect of oral dipyridamole during cerebral hypoperfusion with human carotid endarterectomy. J. Cardiovasc. Pharmacol. 36:141-145.

Littell, R. C., P. R. Henry, and C. B. Ammerman. 1998. Statistical analysis of repeated measures data using SAS procedures. J. Anim. Sci. 76:1216-1231.

Lomba, F. 1996. Influence of dietary cation-anion and oxidative-antioxidants balances on diseases occurring around parturition in the dairy cows. Ann. Med. Vet. 140:109-122.

Maseki, M., I. Nishigaki, M. Hagihara, Y. Tomoda, and K. Yagi. 1981. Lipid peroxide levels and lipids content of serum lipoprotein fractions of pregnant subjects with or without pre-eclampsia. Clin. Chim. Acta 115:155-161.

Michiels, C., M. Raes, O. Toussaint, and J. Remacle. 1994. Importance of Se-glutathione peroxidase, catalase, and $\mathrm{Cu} / \mathrm{Zn}-\mathrm{SOD}$ for cell survival against oxidative stress. Free Radic. Biol. Med. 17:235-248.

Miller, J. K., E. Brzezinska-Slebodzinska, and F. C. Madsen. 1993. Oxidative stress, antioxidants, and animal function. J. Dairy Sci. 76:2812-2823.

Miller, J. K., F. C. Madsen, T. P. Lyons, and K. A. Jacques. 1994. Transition metals, oxidative status, and animal health: Do alterations in plasma fast-acting antioxidant lead to disease in livestock? Biotechnology in the feed industry. Pages 283-301 in Proc. Alltech's Tenth Annu. Symp. T. P. Lyons and K. A. Jacques, ed. Nottingham Univ. Press, Nottingham, UK.

Morrow, J. D. 2003. Is oxidant stress a connection between obesity and atherosclerosis? Arterioscler. Thromb. Vasc. Biol. 23:368370.

Muehlenbein, E. L., D. R. Brink, G. H. Deutscher, M. P. Carlson, and A. B. Johnson. 2001. Effects of inorganic and organic copper supplemented to first-calf cows on cow reproduction and calf health and performance. J. Anim. Sci. 79:1650-1659.

Ozata, M., M. Mergen, C. Oktenly, A. Aydin, S. Y. Sanisoglu, E. Bolu, M. I. Yilmaz, A. Sayal, A. Isimer, and I. C. Ozdemir. 2002. Increased oxidative stress and hypozincemia in male obesity. Clin. Biochem. 35:627-631.

Paglia, D. E., and W. N. Valentine. 1967. Studies on the quantitative and qualitative characterization of erythrocyte glutathione peroxidase. J. Lab. Clin. Med. 70:158-169.
Pigeolet, E., P. Corbisier, A. Houbion, D. Lambert, C. Michiels, M. Raes, M. D. Zachary, and J. Remacle. 1990. Glutathione peroxidase, superoxide dismutase, and catalase inactivation by peroxides and oxygen derived free radicals. Mech. Ageing Dev. 51:283-297.

Rukkwamsuk, T., T. Wensing, and M. J. H. Geelen. 1998. Effect of overfeeding during the dry period on regulation of adipose tissue metabolism in dairy cows during the periparturient period. J. Dairy Sci. 81:2904-2911.

SAS Institute. 1999. User's Guide: Statistics, version 8.0 ed. SAS Institute, Inc., Cary, NC.

Sies, H. 1991. Oxidative stress. Academic Press Ltd., Orlando, FL.

Smith, K. L., J. H. Harrison, D. D. Hancock, D. A. Todhunter, and H. R. Conrad. 1984. Effect of vitamin E and selenium supplementation on incidence of clinical mastitis and duration of clinical symptoms. J. Dairy Sci. 67:1293-1299.

Soltys, K., G. Dikdan, and B. Koneru. 2001. Oxidative stress in fatty liver of obese Zucker rats: Rapid amelioration and improved tolerance to warm ischemia with tocopherol. Hepatology 34:13-18.

Studer, E. 1998. A veterinary perspective of on-farm evaluation of nutrition and reproduction. J. Dairy Sci. 81:872-876.

Toyokuni, S. 1999. Reactive oxygen species-induced molecular damage and its application in pathology. Pathol. Int. 49:91-102.

Treacher, R. J., I. M. Reid, and C. J. Roberts. 1986. Effect of body condition at calving on the health and performance of dairy cows. Anim. Prod. 43:1-6.

Tüzün, A., A. Erdil, V. Inal, A. Aydm, S. Bağci, Z. Yeșilova, A. Sayal, N. Karaeren, and K. Dağalp. 2002. Oxidative stress and antioxidant capacity in patient with inflammatory bowel disease. Clin. Biochem. 35:569-572.

Uleand, P. M., M. A. Mansoor, A. B. Guttormsen, F. Muller, P. Aukrust, H. Refsum, and A. M. Svardal. 1996. Reduced, oxidized and protein-bound forms of homocysteine and other aminothiols in plasma comprise the redox thiol status-A possible element of the extracellular antioxidant defense system. J. Nutr. 126:1281S-1284S.

van den Berg, J. J. M., J. A. F. Op den Kamp, B. H. Lubin, B. Roelofsen, and F. A. Kuipers. 1992. Kinetic and site specificity of hydroperoxide-induced oxidative damage in red blood cells. Free Radic. Biol. Med. 12:487-498.

Vendemiale, G., I. Grattagliano, P. Caraceni, G. Caraccio, M. Domenicali, M. Dall'Agata, F. Trevisani, F. Guerrieri, M. Bernardi, and E. Altomare. 2001. Mitocondrial oxidative injury and energy metabolism alteration in rat fatty liver: Effect of nutritional status. Hepatology 33:808-815.

Weiss, W. P., D. A. Todhunter, J. S. Hogan, and K. L. Smith. 1990 Effect of duration of supplementation of selenium and vitamin E on periparturient dairy cows. J. Dairy Sci. 73:3187-3195.

Yang, S., H. Zhu, Y. Li, H. Lin, K. Gabrielson, M. A. Trush, and A. M. Diehl. 2000. Mithocondrial adaptations to obesity-related oxidant stress. Arch. Biochem. Biophys. 378:259-268. 